\title{
Next Generation Heavy-Lift Launch Vehicle: Large Diameter, Hydrocarbon-Fueled Concepts
}

\author{
Jon Holladay \\ Marshall Space Flight Center \\ Timothy Monk \\ Zero Point Frontiers Corp. \\ Charles Adams \\ Gray Research \\ Ricky Campbell \\ Marshall Space Flight Center
}

With the passage of the 2010 NASA Authorization Act, NASA was directed to begin the development of the Space Launch System (SLS) as a follow-on to the Space Shuttle Program. The SLS is envisioned as a heavy lift launch vehicle that will provide the foundation for future large-scale, beyond low Earth orbit (LEO) missions. Supporting the Mission Concept Review (MCR) milestone, several teams were formed to conduct an initial Requirements Analysis Cycle (RAC). These teams identified several vehicle concept candidates capable of meeting the preliminary system requirements. One such team, dubbed RAC Team 2, was tasked with identifying launch vehicles that are based on large stage diameters (up to the Saturn V S-IC and S-II stage diameters of $33 \mathrm{ft}$ ) and utilize high-thrust liquid oxygen (LOX)/RP engines as a First Stage propulsion system. While the trade space for this class of LOX/RP vehicles is relatively large, recent NASA activities (namely the Heavy Lift Launch Vehicle Study in late 2009 and the Heavy Lift Propulsion Technology Study of 2010) examined specific families within this trade space. Although the findings from these studies were incorporated in the Team 2 activity, additional branches of the trade space were examined and alternative approaches to vehicle development were considered. Furthermore, Team 2 set out to define a highly functional, flexible, and cost-effective launch vehicle concept. Utilizing this approach, a versatile two-stage launch vehicle concept was chosen as a preferred option. The preferred vehicle option has the capability to fly in several different configurations (e.g. engine arrangements) that gives this concept an inherent operational flexibility which allows the vehicle to meet a wide range of performance requirements without the need for costly block upgrades. Even still, this concept preserves the option for evolvability should the need arise in future mission scenarios. The foundation of this conceptual design is a focus on low cost and effectiveness rather than efficiency or cutting-edge technology. This paper details the approach and process, as well as the trade space analysis, leading to the preferred vehicle concept. 


\section{NATIONAL AERONAUTICS AND SPACE ADMINISTRATION}

\section{Next Generation}

Heavy-Lift

Launch Vehicle:

Large-Diameter, Hydrocarbon-Fueled

Concepts

Timothy Monk

Assistant Chief Engineer/Presenter

Jon Holladay

Chief Engineer

IEEE Aerospace Conference

3.6.2012
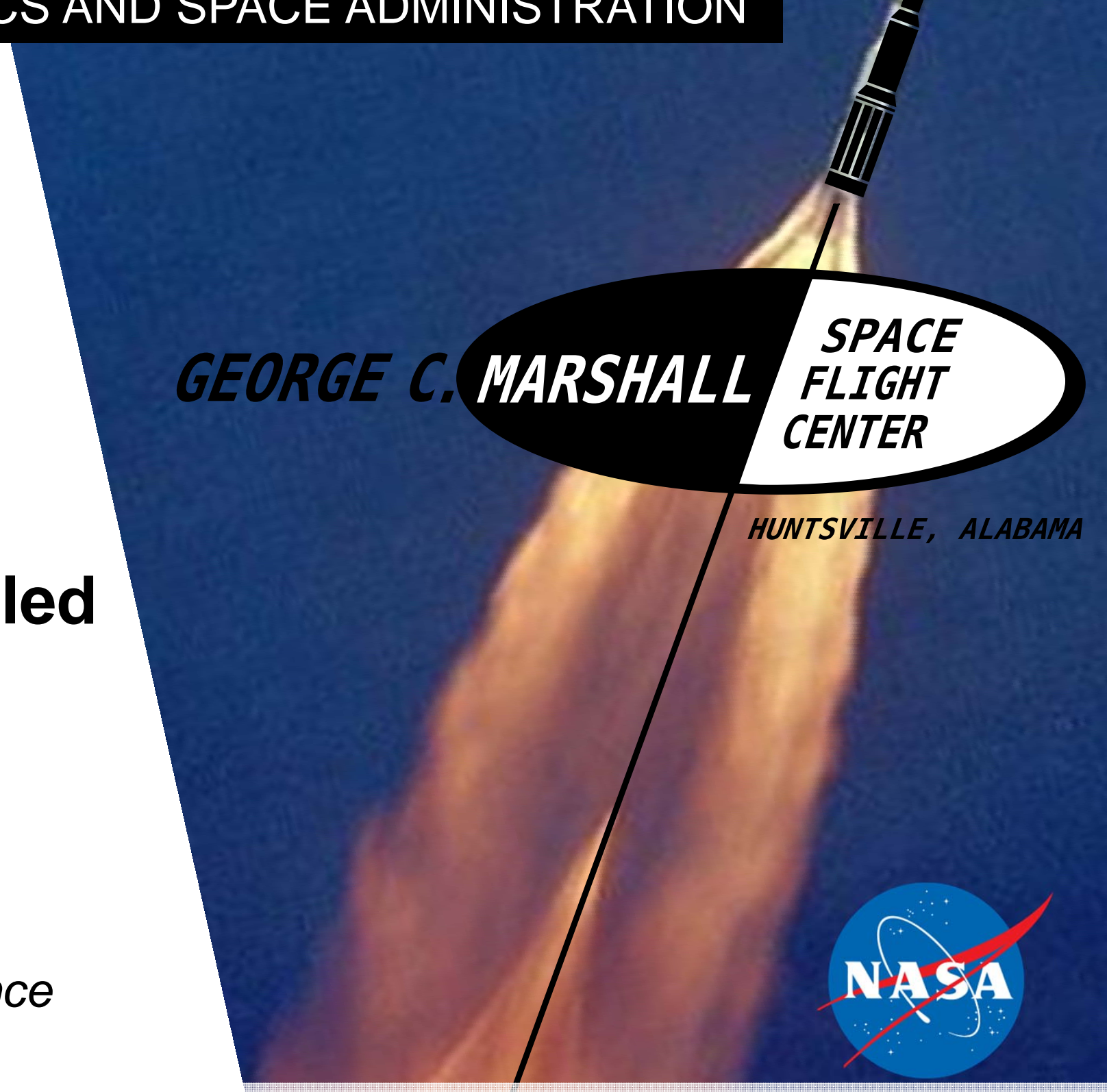

This presentation is providing information regarding NASA's decision process to 


\section{Presentation Summary}

- Requirements Analysis Cycle (RAC) Team 2 Overview

- Challenges with the "Large Diameter, Hydrocarbon-Fueled" Path

- Block Upgrade Approach

- International engines

- "Early 100t" with block upgrade paths beyond 150t

- Delayed Elements Approach

- Delayed First Stage and First Stage Engine

- Commercial Upper Stage

- Delayed Engine

- Flexible, Fixed-Frame Approach

- Small, Medium, Large - whatever performance you need

- Conclusions 


\section{Preamble}

- NASA assessed many potential options for the Space Launch System which could meet the budget, schedule, and performance requirements as given in the NASA Authorization Act of 2010

- A series of in-depth technical and business-case analyses \& studies were conducted by government and industry experts

- The SLS architecture currently in design and development was the sole solution that met the following major requirements:

- First launch in 2017

- Use current contracts, workforce and infrastructure

- Very constrained budget

- The results presented in this paper and presentation by Requirements Analysis Cycle 1, Team 2 are given in historical context only. This is not a revisiting of the decision made by NASA 


\section{SLS Roadmap}

\section{ACTIVITY}

Review of Human Space Flight (HSF) Plans Committee (Augustine Panel)

Heavy Lift Launch Vehicle (HLLV) Study

Heavy Lift Propulsion Technologies Study (HLPT)

Human Exploration Framework Team (HEFT) and HEFT II

Broad Agency Announcements (BAA)

NASA/U.S. Air Force (USAF) Common Engine Study

Heavy-Lift Vehicle (HLV) Analysis of Figures of Merit (FOM)

Requirements Analysis Cycle (RAC) 1

SLS Mission Concept Review (MCR)

Exploration Systems Development (ESD) SLS Analysis of Alternatives (AoA)

Agency Integrated Architecture Decision

SLS Program Planning and Budget Execution for FY13 to Agency

SLS Acquisition Strategy Meeting

Independent Cost Assessment Report (Booz Allen Hamilton)

SLS Rolled out by NASA Administrator

\section{9}

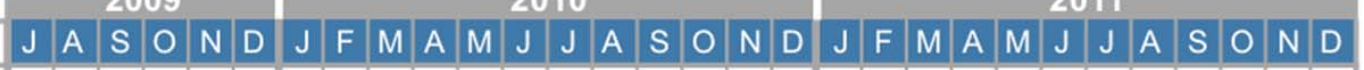

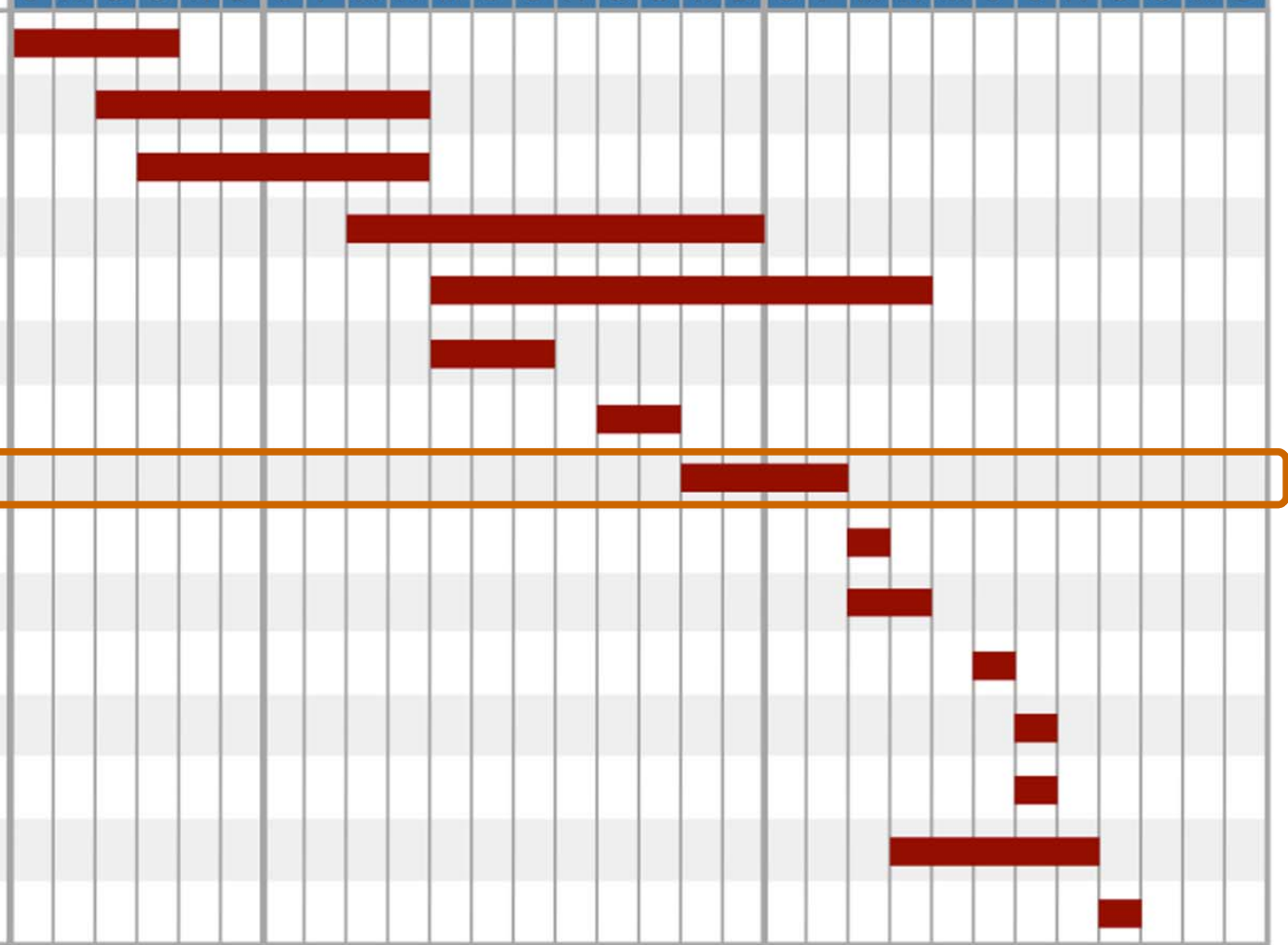




\section{RAC Overview}

- Three "RAC teams" were formed in Fall 2010. These teams were tasked with identifying "feasible vehicle concepts" that had the ability to pass a NASA Mission Concept Review (MCR)

- Draft vehicle requirements were set by the Steering Committee and given to the teams in the form of threshold and objective req'ts

- Generally speaking, the teams formed were:

- Team 1: Shuttle-Derived solutions

- Team 2: Large Diameter, Hydrocarbon-Fueled solutions

- Team 3: Modular Development Approach solutions

- The first of the study cycles ran from November through December, where "midterm results" were presented. The second and final study cycle ran from January through late February.

- Team 2 won the pizza 


\section{Team 2 "Concept Space" Challenges}

- The conceptual trade space was partially developed during the Heavy-Lift Launch Vehicle (HLLV) and Heavy-Lift Propulsion Technology (HLPT) studies (Fall 2009-Spring 2010)

- The primary challenges associated with these vehicle types includes:

- Lack of a domestic, large thrust class LOX/RP engine or Oxygen-Rich Staged Combustion (ORSC) familiarity

- Lack of a large diameter (>27.5') LOX/RP stage

- Lack of a fully-certified LOX/LH2 or LOX/RP upper stage engine

- Lack of a large diameter (>27.5') multi-engine LOX/LH2 or LOX/RP upper stage

- Lack of associated LOX/RP serviceability at test and launch facilities

- These challenges basically influence one major metric:

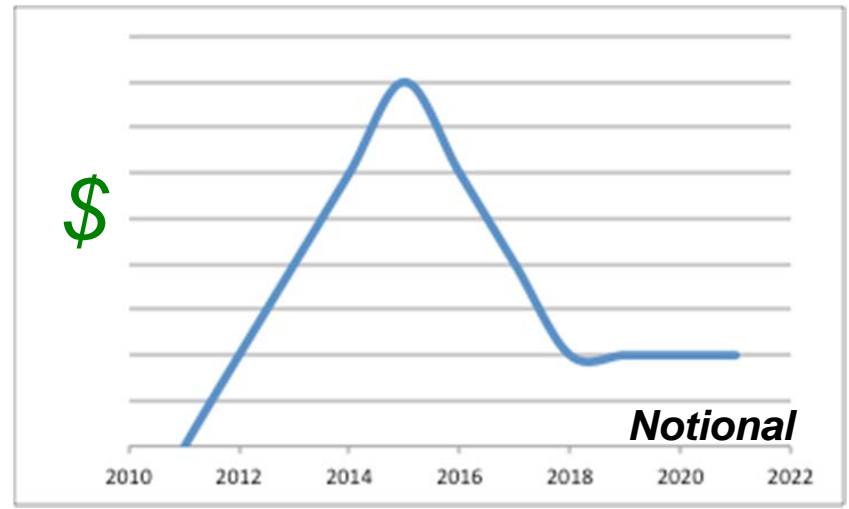




\section{Block Upgrade Approach}

- Team 2 set out to reduce near-term development costs by using smaller, reduced-performance initial vehicle elements. To achieve evolved performance goals, block upgrades were needed.

- Building on the findings from previous studies, the team focused on four basic vehicle families:

- Family 1: 2 Mlbf gas-generator based First Stage with LOX/LH2 Second Stage

- Family 2: 1.25 Mlbf ORSC First Stage with LOX/LH2 Second Stage

- Family 3: 1.25 Mlbf ORSC First Stage with 1.25 Mlbf ORSC Second Stage

- Family 4: Discussed in "Delayed Elements" Approach 


\section{Family 1: 2Mlbf GG Based Concepts}

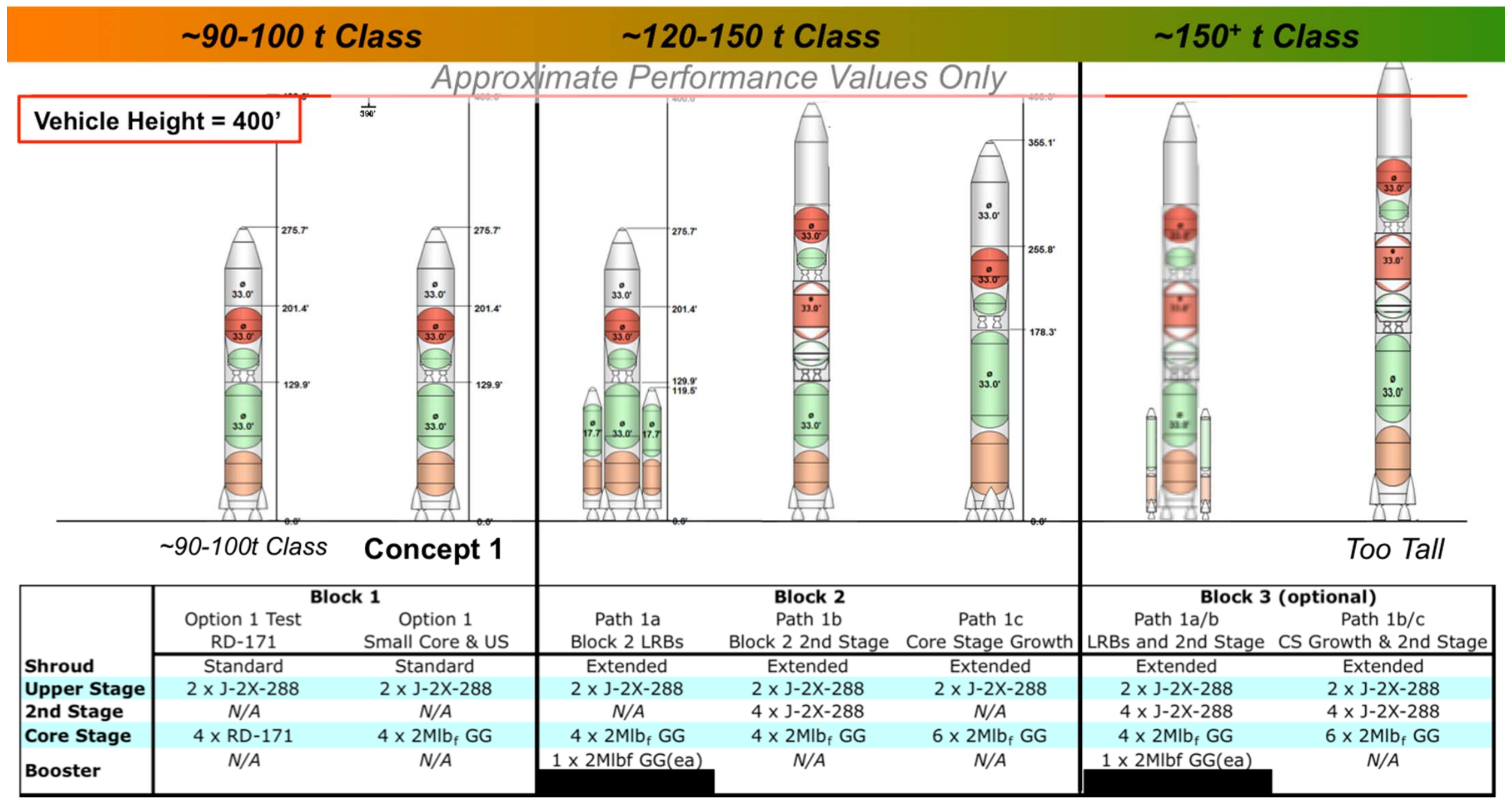




\section{Family 2: 1.25Mlbf ORSC Based Concepts}

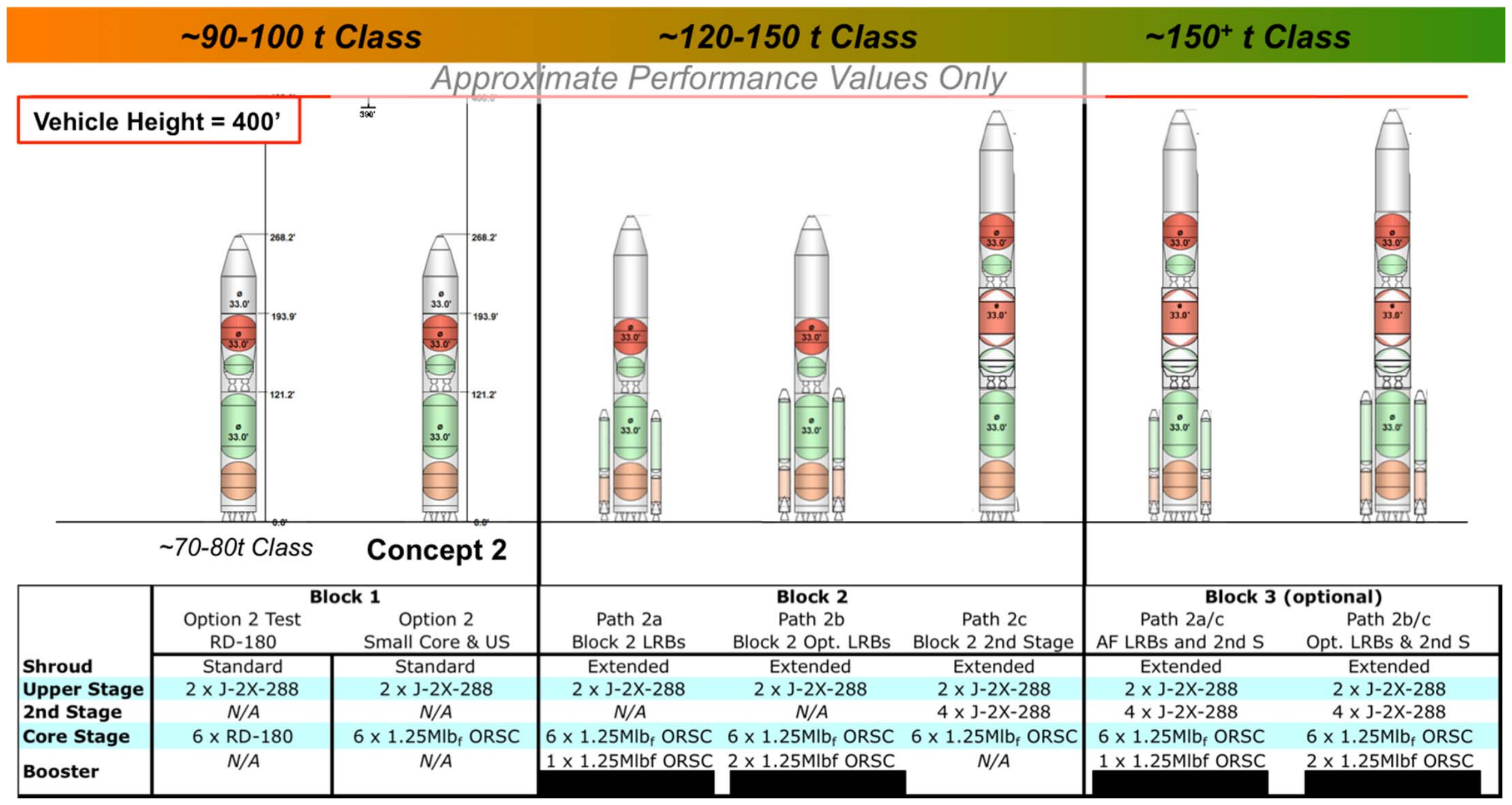




\section{Family 3: $1.25 \mathrm{MIbf}$ ORSC $1^{\text {st }}$ and $2^{\text {nd }}$ Stage Concepts}

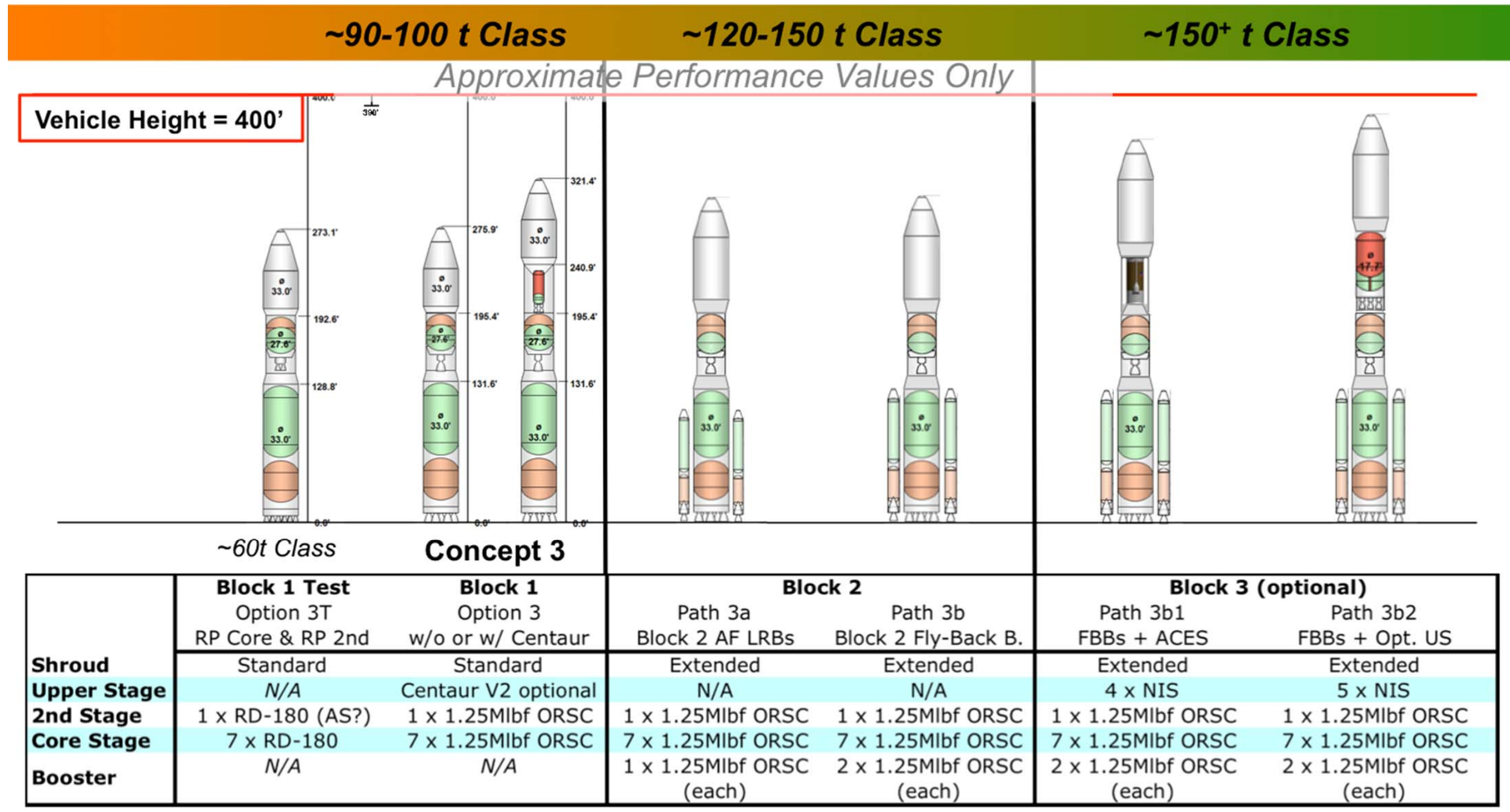




\section{"Delayed Elements" Approach}

- Team 2 explored various paths for establishing a near-term capability with additional growth capabilities

- This included:

- Family 4: Delayed LOX/RP engine approach

- Delayed Upper Stage approach (commercial stage utilization)

- Delayed Upper Stage engine approach (SSME potential) 


\section{Family 4: Delayed RP First Stage}

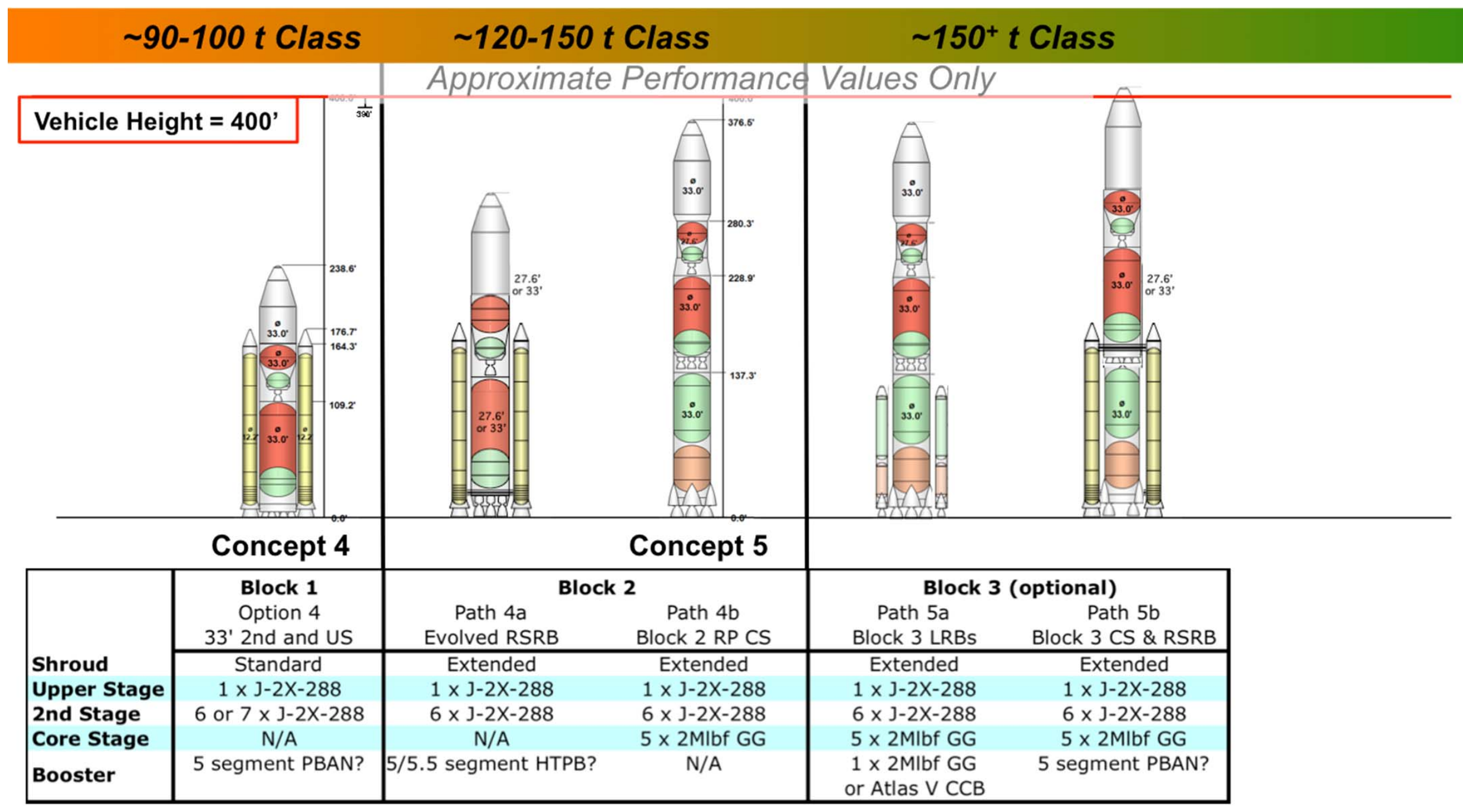




\section{Delayed Upper Stage Approach}

- Concept 2 utilized $6 \times 1.25$ Mlbf ORSC Core Stage Engines and $2 \times$ J-2X-288 Upper Stage Engines

- If near-term cost projections are still too high for this lower performance class case, can the Upper Stage be delayed?

- Performance Class is as follows with a variety of commercially available Upper Stages:
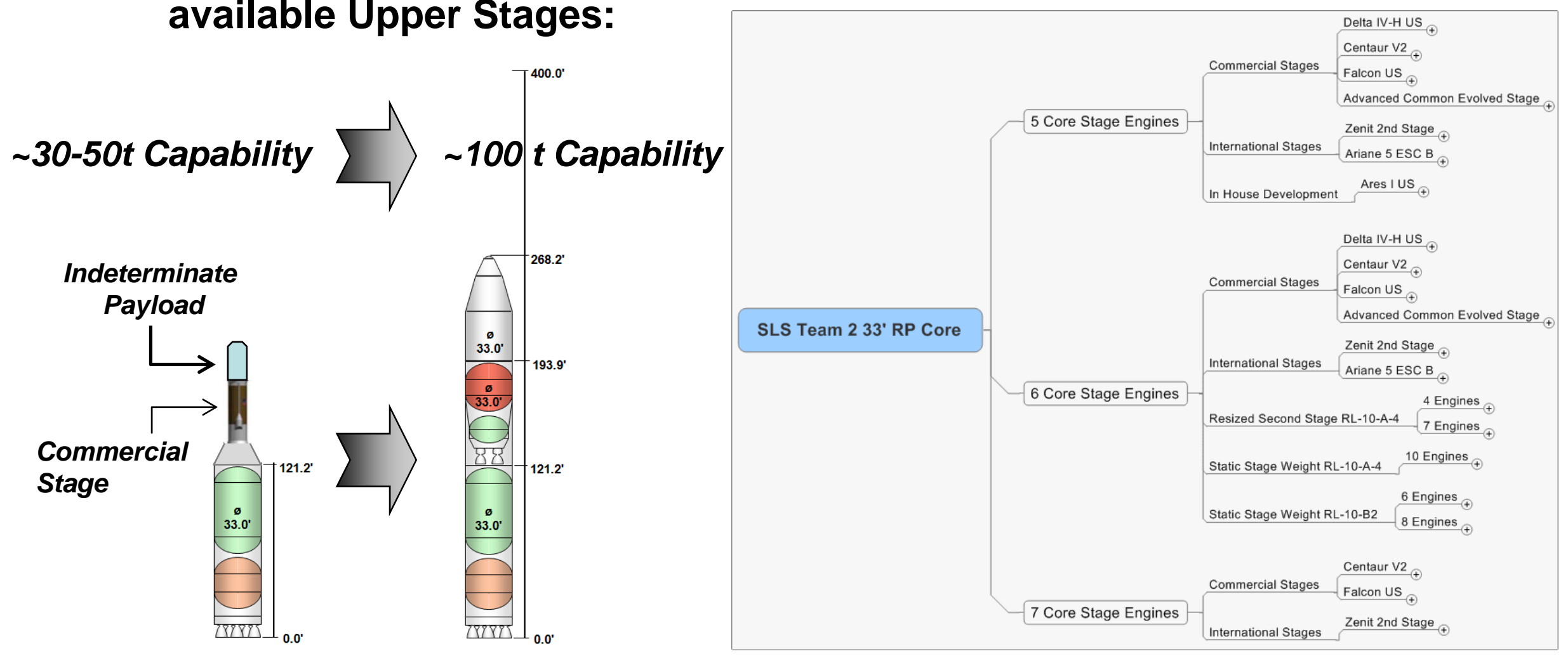

Notional 


\section{Delayed Upper Stage Engine}

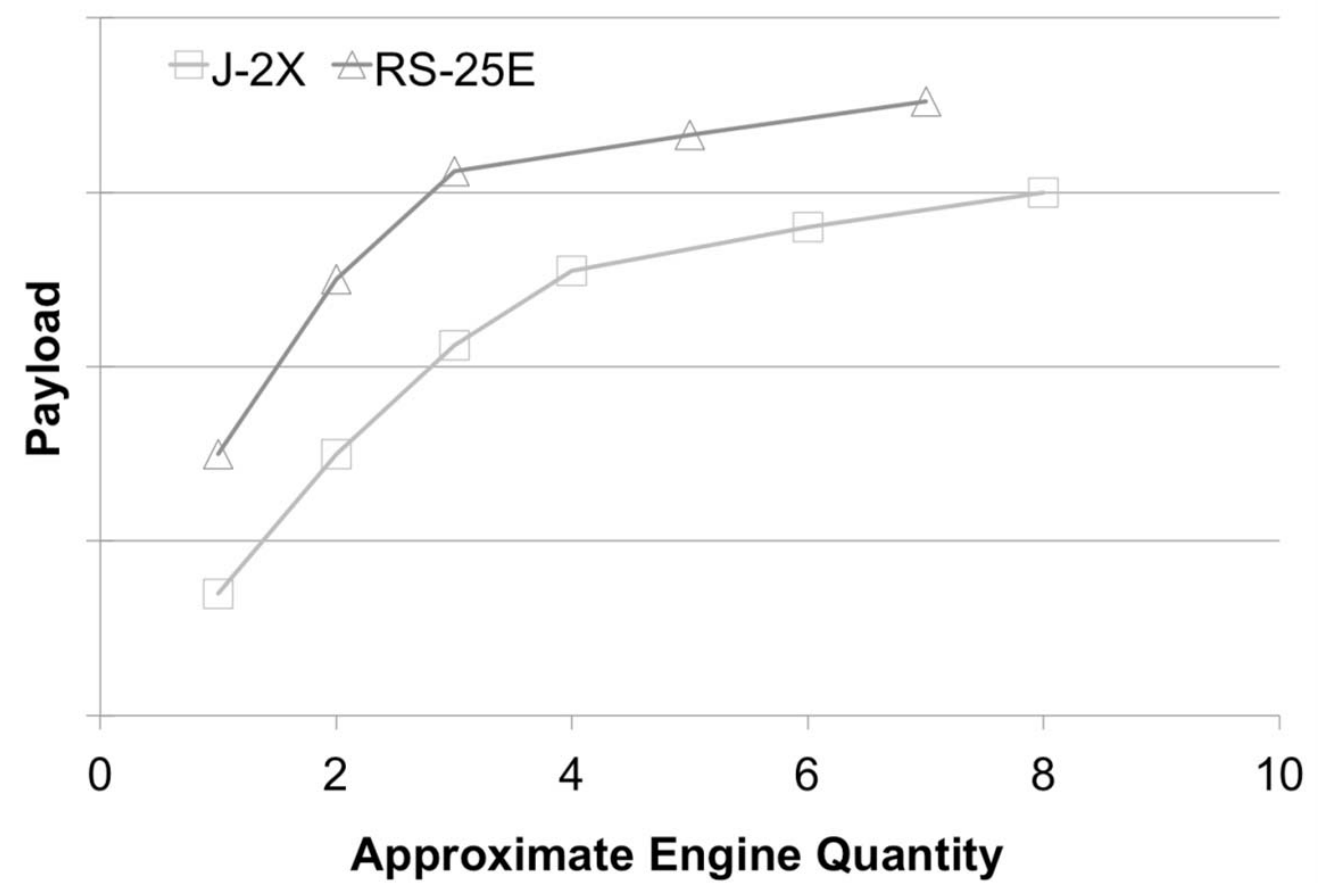

- A vehicle configuration was flown wl RS-25Es rather than J-2Xs

- Trend shows that equivalent LV performance can be realized by replacing $\sim 2 \mathrm{~J}-2 \mathrm{X}$ s with $\sim 1 \mathrm{RS}-25 \mathrm{E}$

- 10-15t of additional performance available by replacing $5 \mathrm{~J}-2 \mathrm{X}$ with 4 RS-25E

- Detailed Cost, Reliability, Engine Availability, Schedule assessment needs to characterize full impact of RS-25E vs. J-2X 


\section{Flexible Fixed Frame Approach}

- The team sought to evaluate a method of producing a single vehicle "tank set" which would provide the following benefits:

- Flexible "engine dialing" based on mission performance requirements

- Lower cost by minimizing unique developments

- Lower cost by maintaining common ground support infrastructure

- Elimination of the need for performing block upgrades

- The team evaluated the vehicle "family" from which to perform this evaluation and propose a "recommended vehicle"

- The team also evaluated which performance class to optimize around....(minimization of inefficiencies) 


\section{Flexible, Fixed-Frame Approach: Downselection}

High-Level Trade Study Results

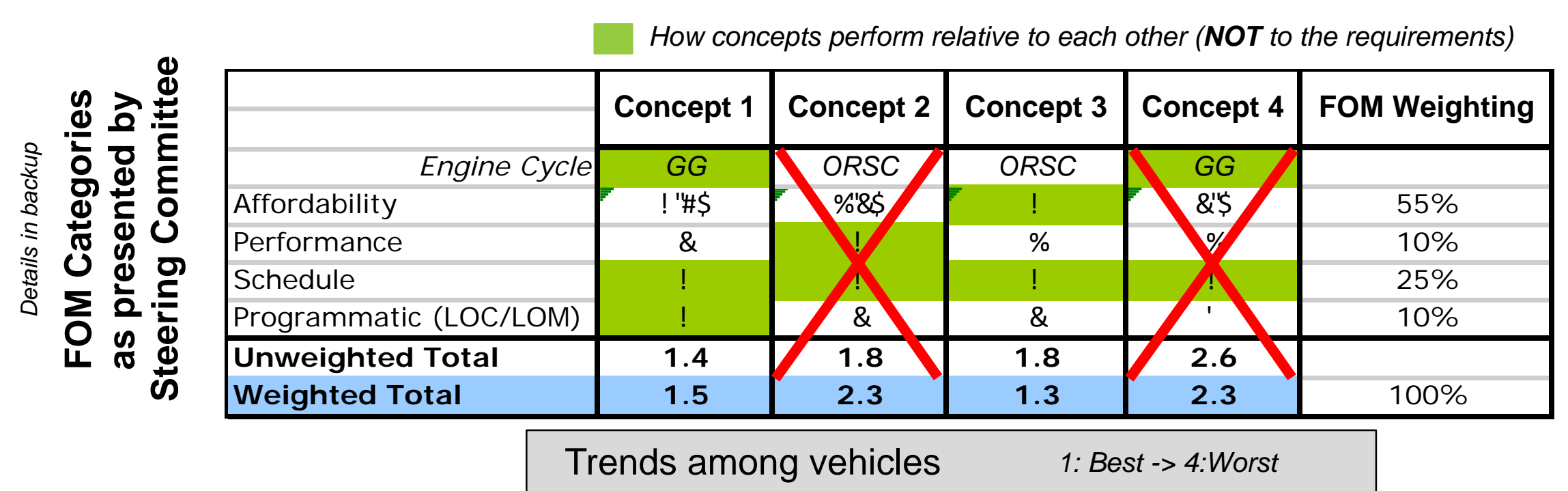

Initial Downselect: Concepts $2 \& 4$ do not score as well as Concepts 1 \& 3

Concept 1 Family chosen over Concept 3 Family due to lower engine development risk and less costly growth options availability 


\section{Flexible Fixed Frame Approach: Options}

\section{Increasing Performance}

2-Stage In-line Vehicle is Capable of Meeting Virtually Any LEO Performance Requirement $<200 t$

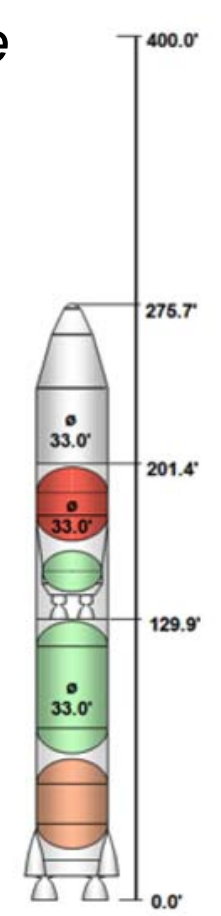

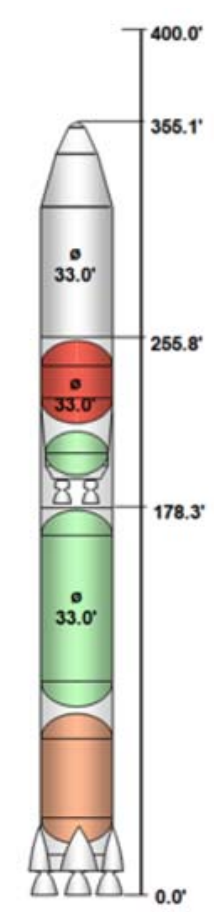
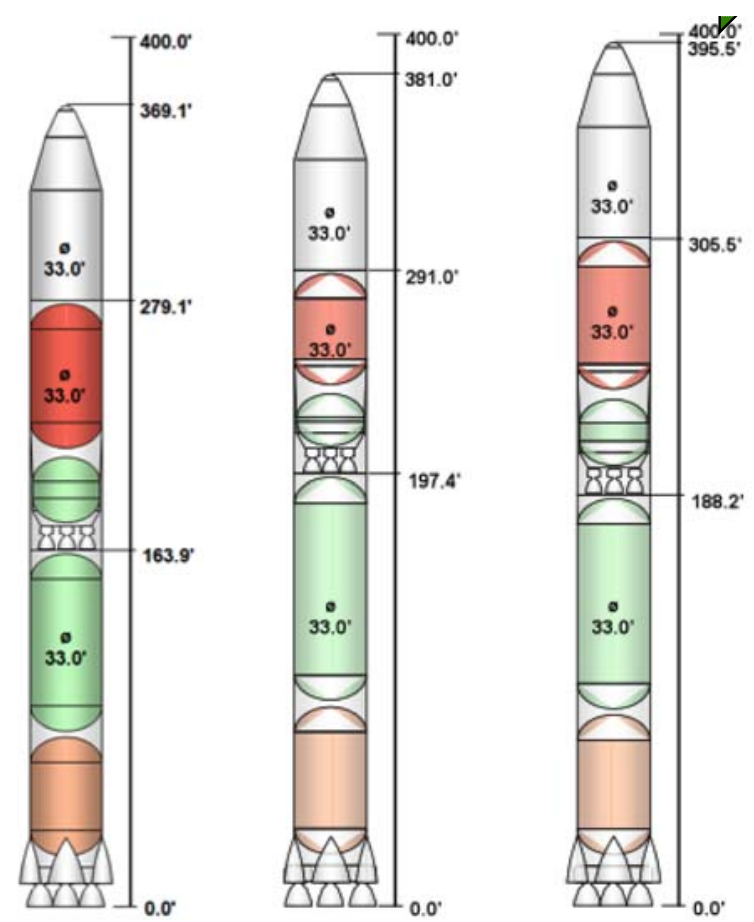

"5-3"

"6-2"

"6-5"

"7-3"

“7-5"

\begin{tabular}{|c|c|c|c|c|c|c|}
\hline ACO Designation & 131.03 .00 & 131.10.00 & 131.00 .00 & 131.17.03 & 131.05 .05 & 131.06 .03 \\
\hline $1^{\text {st }}$ Stage Engines & $4 \times 2 \mathrm{Mlb}_{\mathrm{f}} \mathrm{GG}$ & $5 \times 2 \mathrm{Mlb}_{\mathrm{f}} \mathrm{GG}$ & $6 \times 2 \mathrm{Mlb}_{\mathrm{f}} \mathrm{GG}$ & $6 \times 2 \mathrm{Mlb}_{\mathrm{f}} \mathrm{GG}$ & $\begin{array}{c}7 \times 2 \mathrm{Mlb}_{\mathrm{f}} \\
\mathrm{GG}\end{array}$ & $7 \times 2 \mathrm{Mlb}_{\mathrm{f}} \mathrm{GG}$ \\
\hline $2^{\text {nd }}$ Stage Engines & $2 x J-2 x$ & $3 x J-2 x$ & $2 x J-2 x$ & $5 x J-2 x$ & $3 x J-2 x$ & $5 x J-2 x$ \\
\hline
\end{tabular}




\section{Fixed Frame Approach}

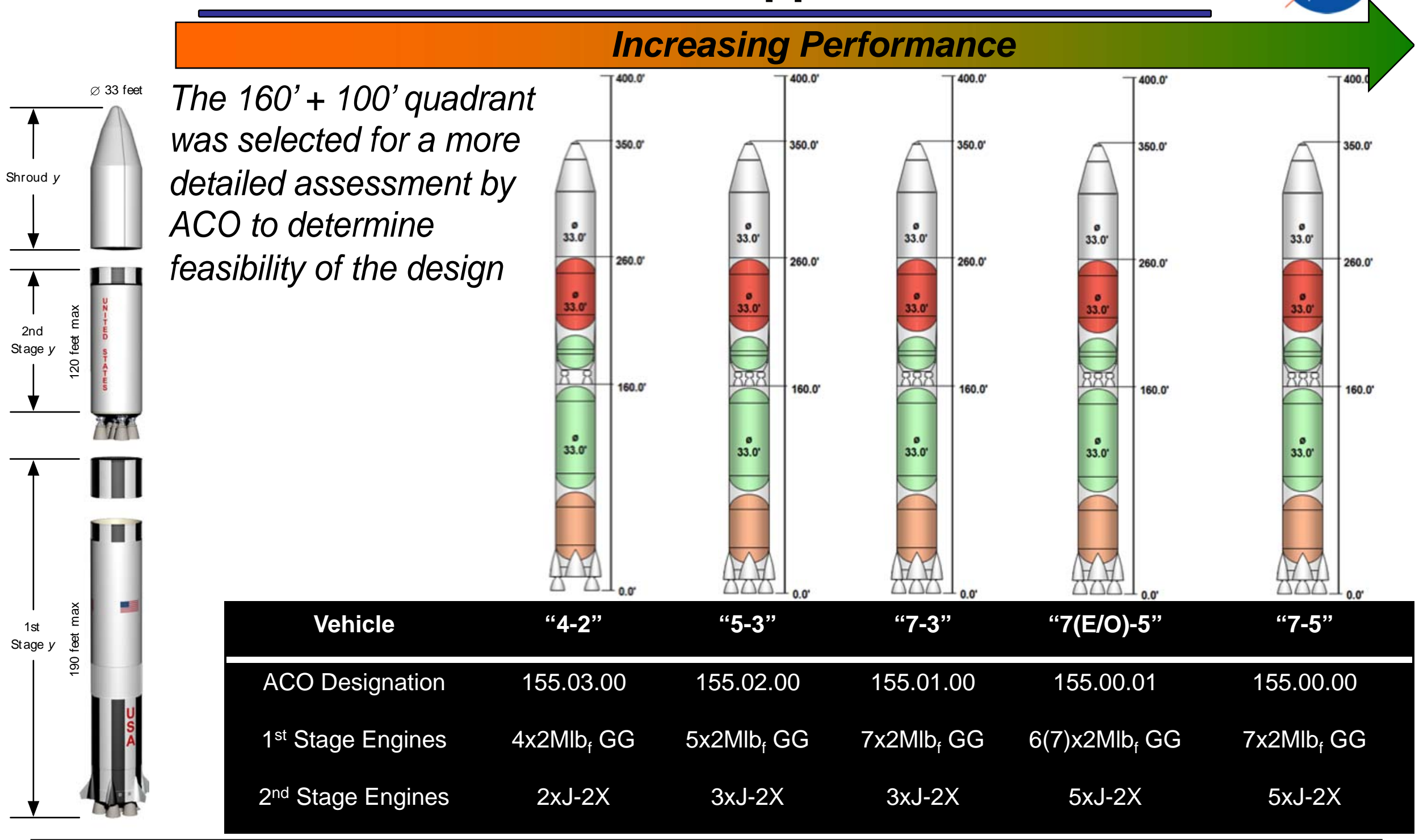

Four fixed frame options were explored. More detailed assessment required to find most efficient stage length combinations. 


\section{Conclusions}

- Relatively large trade space around LOX/RP concepts was explored during the Requirements Analysis Cycle

- Multiple development approaches were explored in order to address the challenges associated with this vehicle type

- A downselection was made to GG-based concepts in order to facilitate a more thorough exploration within a single family

- A "fixed frame" concept approach was presented which provided multiple benefits over the life of the program

- This "fixed frame" approach provided vehicles which met the Steering Committee draft threshold requirements and provided ample margin in a variety of areas. 